\title{
A comparative study using a fluorescence-based and a direct-count assay to determine cytotoxicity in Tetrahymena pyriformis
}

\author{
Nicolina Dias, Nelson Lima* \\ Centro de Engenharia Biológica, IBQF, Universidade do Minho, Campus de Gualtar, 4710-057 Braga, Portugal \\ Received 10 October 2001; accepted 16 April 2002 \\ First published online 14 May 2002
}

\begin{abstract}
A novel cellular cytotoxicity assay using two fluorescent dyes was developed as an alternative method to the standard direct count of viable protozoa under light microscopy. The compound calcein AM is a non-fluorescent substance that diffuses passively across intact cell membranes and is converted by intracellular esterases to the green fluorescent calcein, which is retained in viable cells. The addition of EthD-1 that binds to DNA stained nuclei of dead cells red. The experiments were carried out in order to assess viability in the freshwater ciliate Tetrahymena pyriformis after exposure to eight surfactants, two of each representing one of four ionic class (non-ionic, anionic, cationic and amphoteric), and two heavy metals, copper and zinc, at several concentrations. In earlier time exposure, less than one hour of contact with surfactants at sublethal concentrations, the fluorescent method is more sensitive and provides more accurate results than direct counting under light microscopy. In contrast, with increasing time exposure, the results obtained by the two methods were similar. Calcein was shown to be a poor viability marker in the presence of zinc and copper since the fluorescence intensity was affected by the metal presence. However, the fluorescent method offers new opportunities to use advanced techniques, such as flow cytometry, to assess cytotoxicity in protozoa. () 2002 Éditions scientifiques et médicales Elsevier SAS. All rights reserved.
\end{abstract}

Keywords: Calcein AM; Ciliated protozoa; Cytotoxicity assay; EthD-1

\section{Introduction}

Cytotoxicity and cell death have been evaluated by the use of markers either retained by living cells $[3,20]$, or released from lysed cells $[8,24,30]$. Fluorogenic derivatives that are substrates for esterases stain live cells, and are widely used as cytoplasmic markers and viability probes [8].

Calcein AM is a non-fluorescent lipophilic ester that diffuses passively into cells and is cleaved by intracellular esterases to fluorescent calcein [9]. Once hydrolyzed, highly negative charged free calcein is lipid-insoluble, being trapped inside cells with intact membranes, and becomes fluorescent green at $530 \mathrm{~nm}$. A second dye is added to stain dead cells. EthD-1 (ethidium homodimer) is a cell impermeant fluorochrome that passes through compromised membranes, strongly binds to double-stranded nucleic acids and emits red fluorescence at $617 \mathrm{~nm}$.

Ciliated protozoa have a wide distribution in aquatic environments [11]; they are an important component of the

\footnotetext{
* Correspondence and reprints.

E-mail address: nelson@iec.uminho.pt (N. Lima).
}

aquatic food chain [23] and play an essential role in the purification processes of both aerobic and anaerobic biological wastewater treatment systems. Their sensitivity to environmental changes suggested their use as biological indicators of water pollution [15]. Among protozoa, the ciliate Tetrahymena pyriformis is the most commonly ciliated model used for laboratory research [25]. It was the first protozoon to be cultivated axenically, which could explain the extensive use of Tetrahymena sp. as a model cell system since, in principle, the addition of a test compound may be the only change in culture conditions [18]. Therefore, under axenic culture conditions, standardization and guarantee of reproducibility of assays are obtained [28]. In the present study, T. pyriformis was used as a test organism for the assessment of cytotoxicity in protozoa exposed to several concentrations of eight surfactants and two heavy metals. Surfactants are surface-active compounds that interact with cell membranes resulting in their damage at higher concentrations. Two of each ionic class were tested. Anionic surfactants, SDS and DBSA differ from the chemical structure but have the same alkyl chain length. Cetylpyridinium chloride and hexadecyltetramethylammonium chloride are 
two quaternary ammonium salts and were tested as cationic ions. Triton X-100 and Tween- 80 were used as neutral surfactants. Finally, amphoteric surfactants, Zwittergent-08 and Zwittergent-16 differ only in the aliphatic chain length. Copper and zinc are two essential micronutrients required for growth and metabolism but became potentially toxic in excess amounts. Viable green cells versus red dead cells could be detected by fluorescence microscopy. Quantification and data analysis may then be performed by advanced techniques such as microfluorometry $[1,30]$, flow cytometry $[2,20]$ or confocal laser microscopy [5]. It is expected that this assay will represent a sensitive method for cytotoxicity evaluation, when compared with the traditional direct-count assay based on morphological and motility changes.

\section{Materials and methods}

\subsection{Organism and medium}

Cytotoxicological assays were performed with an 18$24 \mathrm{~h}$ old culture of Tetrahymena pyriformis strain GL, ref. CCAP/1630/1F from the catalogue of Strains of Culture Collection of Algae and Protozoa, UK. The culture was grown axenically to exponential phase to a density of approximately $10^{4}$ cells $/ \mathrm{ml}$, at room temperature, $\mathrm{pH} 7.0-7.5$. Its duplication time under control conditions was about 6 to $7 \mathrm{~h}$. Proteose peptone yeast extract medium (PPY), proteose peptone $2 \%$ and yeast extract $0.25 \%$ made up the culture medium used for growth. The medium was filtered twice $(0.45 \mu \mathrm{m}$ membrane porosity) before autoclave sterilization, and before the culturing step, to avoid particle background on fluorescence microscopy. For cytotoxicological assays initial densities of cultures reached about 5000 to 8000 cells $/ \mathrm{ml}$. In order to confirm that the small volume of the test tubes did not cause poor oxygenated conditions for the cells two assays were performed: a total culture volume of $1.5 \mathrm{ml}$ was used in a 2-ml Eppendorf tube and in a 12-ml plastic test tube. A high correlation $\left(r^{2}=0.989\right)$ of growth rate was obtained in these two assays.

\subsection{Toxicants and concentrations}

Toxicant concentrations were arranged in order that the lowest concentration should have no effect on cell viability and the highest concentration should cause more than $50 \%$ loss of viability.

\subsubsection{Surfactants}

The following set of surfactants was chosen to include two of each of all ionic classes and a wide range of physicochemical properties.

SDS (sodium dodecyl sulfate) (Sigma-Aldrich, Germany) was used at $0.0001,0.001$ and $0.01 \mathrm{mg} / \mathrm{ml}$. DBSA (dodecyl benzene sulfonic acid) (Sigma-Aldrich, Germany) was used at $0.001,0.005$ and $0.01 \mathrm{mg} / \mathrm{ml}$. Cetylpyridinium chloride (Sigma-Aldrich, Germany) was used at $0.001,0.002$ and $0.005 \mathrm{mg} / \mathrm{ml}$. Hexadecyltetramethylammonium chloride (Sigma-Aldrich, Germany) was used at $0.0001,0.0002$ and $0.0005 \mathrm{mg} / \mathrm{ml}$. Triton X-100 (octylphenoxypolyethoxyethanol) (Merk, Germany) was used at 0.01 , 0.05 , and $0.1 \mathrm{mg} / \mathrm{ml}$. Tween-80 (polyethylene (20) sorbitan monooleate) (Sigma-Aldrich, Germany) was used at 1, 10 and $100 \mathrm{mg} / \mathrm{ml}$. Zwittergent-08 (Calbiochem, US) was used at $12.5,15$ and $20 \mathrm{mg} / \mathrm{ml}$. Zwittergent-16 (Calbiochem, US) was used at $0.08,0.1$, and $0.2 \mathrm{mg} / \mathrm{ml}$.

All of the surfactants except hexadecyltetramethylammonium chloride were dissolved in distilled water and sterilization was performed by filtration $(0.2 \mu \mathrm{m})$. If necessary, $\mathrm{pH}$ was adjusted to 7.0 to 7.5. Hexadecyltetramethylammonium chloride was diluted in a 50\% solution 2-propanol/water $3: 2$, due to it hydrophobicity. In this proportion and for the concentrations used, the solvent had no cytotoxic effect.

\subsubsection{Heavy metals}

Copper, as $\mathrm{CuCl}_{2} \cdot 2 \mathrm{H}_{2} \mathrm{O}$ (Merk, Germany) and zinc as $\mathrm{ZnCl}_{2}$ (Merk, Germany), were used at four nominal concentrations: $0.50,0.75,0.90$ and $1.0 \mathrm{mg} / \mathrm{ml}$ and 0.2 , $0.3,0.4$ and $0.5 \mathrm{mg} / \mathrm{ml}$, respectively. Stock solutions were prepared in distilled water to avoid chemical binding to the medium and sterilization was performed by filtration $(0.2 \mu \mathrm{m})$. The $\mathrm{pH}$ was adjusted to 7.0 to 7.5 , by the addition of $0.1 \mathrm{~N} \mathrm{NaOH}$. The $\mathrm{pH}$ values did not change during the assay. A control assay using sodium chloride was performed prior to the toxicity tests to investigate the influence of chloride present in the heavy metal solution on cell viability. No detectable effect on growth ability was observed in the used equimolar chloride concentrations.

Soluble concentrations of heavy metals were obtained after dialysis of the PPY medium through a Pierce Snakeskin $^{\mathrm{TM}}$ pleated dialysis tubing (Pierce, USA) 3500 Da (molecular cut-off). Dialysis was performed, following with minor modifications the procedure described by Nicolau et al. [15]. Zinc remaining in the medium was determined by a SpectrAA-250 plus (VARIAN) atomic absorption spectrophotometer, equipped with a GTA-96 graphite tube atomizer and hollow cathode lamps for copper and zinc. Calculation of the amount of metal bound to the dissolved organic matter, allowed the determination of the effectively bio-available fraction of each metal (Table 1).

\subsection{Fluorescent probes}

Cells were labelled with a freshly made solution of dyes taken from the Live/Dead ${ }^{\circledR}$ viability/cytotoxicity assay kit (Molecular Probes Europe BV, The Netherlands) at final working concentrations of $10 \mu \mathrm{M}$ calcein $\mathrm{AM}$ [4'5'-bis $\left(\mathrm{N}^{\prime} \mathrm{N}^{\prime}\right.$-bis (carboxymethyl) aminomethyl fluorescein acetoxymethyl ester)] and $2.5 \mu \mathrm{M}$ EthD-1 (ethidium homodimer-1) in phosphate buffer solution (PBS). No cytotoxic effects of calcein AM and no protozoan autofluo- 
Table 1

Nominal and soluble concentrations of the heavy metal toxicants used in the present study

\begin{tabular}{ccc}
\hline $\begin{array}{c}\text { Metal nominal } \\
\text { concentration }(\mathrm{mg} / \mathrm{ml})\end{array}$ & \multicolumn{2}{c}{ Soluble metal concentration $(\mathrm{mg} / \mathrm{ml})$} \\
\cline { 2 - 3 } & Copper & Zinc \\
\hline 0.20 & - & 0.05 \\
0.30 & - & 0.09 \\
0.40 & - & 0.16 \\
0.50 & 0.37 & 0.25 \\
0.75 & 0.55 & - \\
0.90 & 0.64 & - \\
1.00 & 0.69 & - \\
\hline
\end{tabular}

rescence were observed under the experimental conditions. Storage and handling of reagents were performed as recommended by the supplier.

\subsection{Cytotoxicity assays}

T. pyriformis was exposed to the toxicants for a 48$\mathrm{h}$ experiment and assays were performed at 0.1, 1, 24 and $48 \mathrm{~h}$ of toxicant exposure. For each toxic agent, at least two independent assays were carried out with two to four replicates. As control for each toxicant three supplementary sets of two replicates, without toxicants, were used. The untreated and the treated suspended $T$. pyriformis were incubated on 2-ml Eppendorf tubes in a total volume of $1.5 \mathrm{ml}$, at room temperature. The tubes were centrifuged before the assay at 13000 r.p.m. for 1 min in order to settle down and concentrate the cells. The cytotoxicity of toxicants was expressed as a percentage of control.

\subsubsection{Light microscopy counting}

Total and dead cell numbers were estimated by conventional direct counting under observation at $400 \times$ magnification in an inverted microscope (NIKON Diaphot 300), as described elsewhere [15]. For each subsample, a drop of $30 \mu \mathrm{l}$ was taken from the Eppendorf tube and dead cells were counted as non-motile cells or cells with changed morphology. The total number of individuals was counted after fixation with $10 \mu \mathrm{l}$ of formalin $4 \%$ in distilled water. Percentage of viability was determined as following:

Viability $(\%)=[($ total cells - dead cells $) /$ total cells $] \times 100$

\subsubsection{Fluorescence microscopy counting}

A drop of $30 \mu \mathrm{l}$ of the cell suspension was taken from the Eppendorf tube and transferred to a glass microscope slide. $15 \mu \mathrm{l}$ of the dye solution was added. The cells were incubated for 30-45 $\mathrm{min}$ at room temperature. After cell loading, a drop of $10 \mu \mathrm{l}$ of gum arabic (Sigma, USA) (10\% w/v in PBS) and $20 \mu \mathrm{l}$ of fixative containing glutaraldehyde $0.2 \%$ (Merk, Germany) and formamide $2 \%$ (Sigma, USA) in PBS [19] were added to a clean $24 \times 32 \mathrm{~mm}$ coverslip. The coverslip was carefully inverted on the slide to prevent damaging the cells.
A fluorescence microscope (Zeiss Axioskop) supplied with an HBO 50 mercury lamp as light source and a filter set (EX 450-490 nm, EM $520 \mathrm{~nm}$ ) was used in order to carry out the observations and cell counting.

Green immobilized cells were counted as viable cells and red cells or double stained green-red cells were counted as non-viable cells. Viability was determined as the number of green cells counted among a total of 100 cells observed at random.

Photomicrographs were taken with a camera, (ZEISS MC 100) coupled to the fluorescence microscope. Fujicolor (800 ASA) and Fujichrome Provia (1600 ASA) were the films used in all the experiments.

\subsubsection{Recovery assay}

The reversibility of the toxicant effects was determined as the ability of injured cells to return to their normal shape and growth pattern.

T. pyriformis was grown for $24 \mathrm{~h}$ in fresh PPY in order to reach the exponential phase. Then $500 \mu \mathrm{l}$ of the suspension was added to test tubes containing the highest toxicant concentration. Immediately after the contact (about $1 \mathrm{~min}$ ) $500 \mu \mathrm{l}$ aliquots were transferred without centrifugation into $4.5 \mathrm{ml}$ fresh PPY medium. Since cells were not washed because of their membrane fragility, it should be considered that the toxicant was not totally removed from the medium, and was present in a diluted (about 1:10) and non-cytotoxic concentration of toxicant. The observations and counting were performed at $0.1,24$ and $48 \mathrm{~h}$.

\section{5. $L C_{50}$ determination}

Data expressed resulted from the mean values of at least four experiments. The $50 \%$ lethal concentration $\left(\mathrm{LC}_{50}\right)$ and correlation coefficients were calculated by regression analysis.

\section{Results}

\subsection{Estimation of viability under light and fluorescence microscopy}

\subsubsection{Control}

Under light microscopy untreated cells showed a normal morphology, normal swimming pattern and high mobility. A few non-motile cells were found after $24 \mathrm{~h}$ of incubation in all the experiments. Under fluorescent microscopy untreated cells exhibited a normal morphology, presenting green vacuoles which fluorescence intensities reflected the intracellular distribution of esterase and their activities (Fig. 1).

\subsubsection{Surfactant treated cells}

At lower concentrations, any used surfactants affected cell morphology, swimming pattern and speed. Under fluorescence microscopy $T$. pyriformis showed a bright green fluorescence similar to that observed in control cells. 


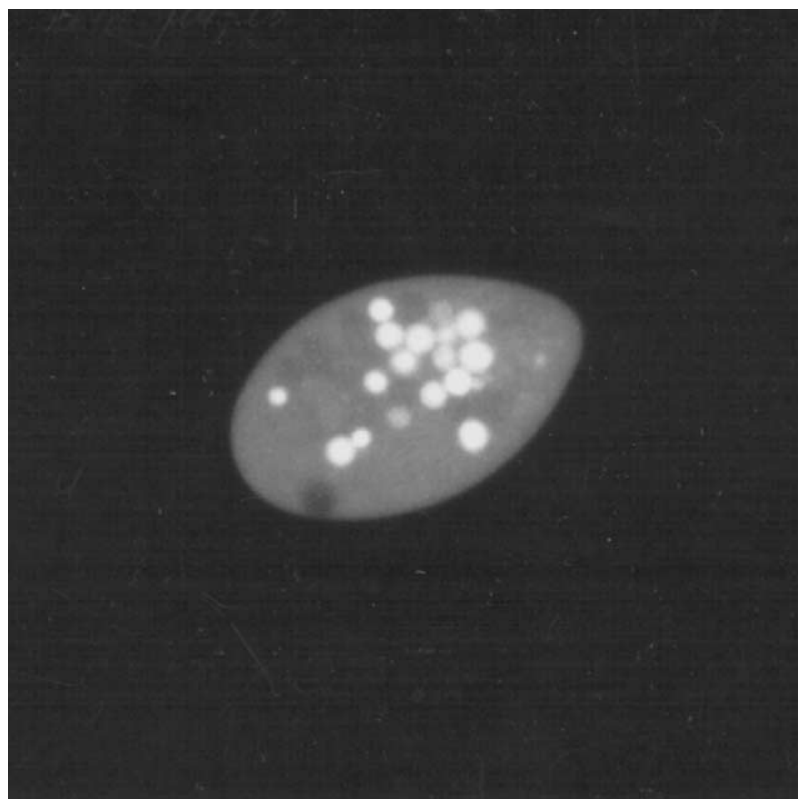

Fig. 1. T. pyriformis observed under fluorescence microscopy after staining with calcein $\mathrm{AM} / \mathrm{EthD}-1.400 \times$ magnification.

An increasing number of cells treated with surfactants at intermediate to highest concentrations showed an altered round shape and became immobile at earlier time $(0.1$ to $1 \mathrm{~h}$ ) of toxicant exposure. Under light microscopy those cells were detected as abnormally shaped cells and were counted as dead cells (Fig. 2a). A major feature of the calcein AM/Ethd-1 assay was the ability to visualize the cell viability/mortality on a fluorescence microscope and to distinguish two different populations on the same sample. As EthD-1 only penetrated into cells with membrane damage, round cells stained with the nuclear dye were counted as dead cells. Surprisingly, a large fraction of round cells exhibited a green stain instead of the expected red staining (Fig. 2b). Taking into account that all green cells corresponded to cells without compromised membranes, if round shaped green cells were really viable, it is expected that they would recover their normal morphology after toxicant removal.

DBSA, cetylpyridinium chloride, hexadecyltrimethylammonium chloride and Triton X-100 treated cells with the highest concentration became round and were counted as dead cells by light microscopy after $0.1 \mathrm{~h}$ of injury (Table 2). In contrast, up to $60 \%$ of those cells stained green, and were counted as viable cells by fluorescence microscopy. In order to assess viability of altered green stained cells a recovery assay was performed. Cells transferred from the highest concentration in all surfactants to fresh PPY recovered their morphology and viability. Except for SDS, where slight growth was observed at $48 \mathrm{~h}$ of exposure, no cell recovery was observed after $1 \mathrm{~h}$ of exposure to the highest concentration of the surfactants tested. Despite the fact that $T$. pyriformis treated with Tween- 80 showed few green vacuoles and a strong decrease in fluorescence, no recovery

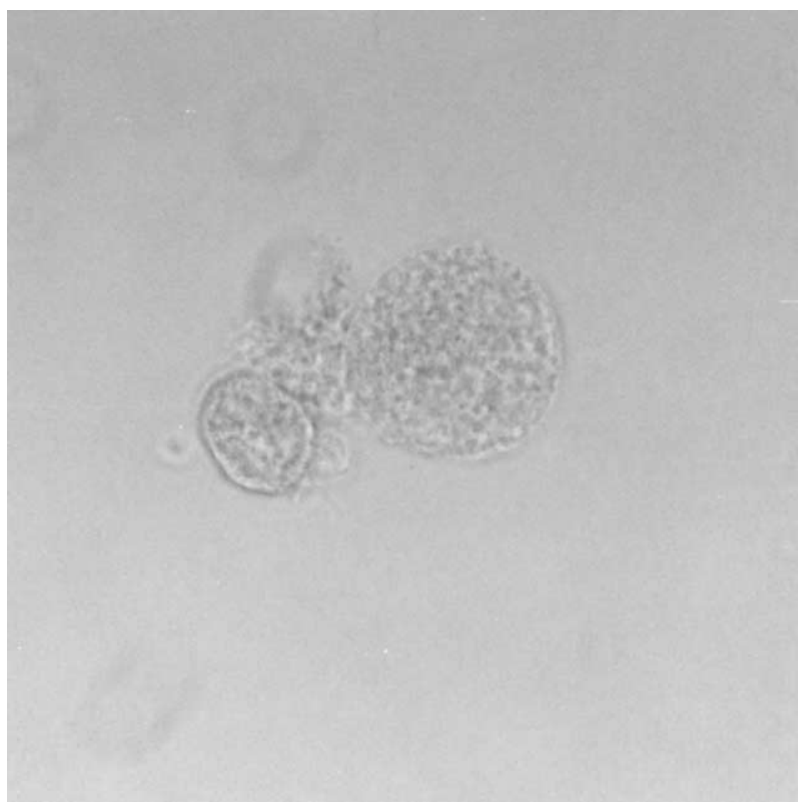

(a)

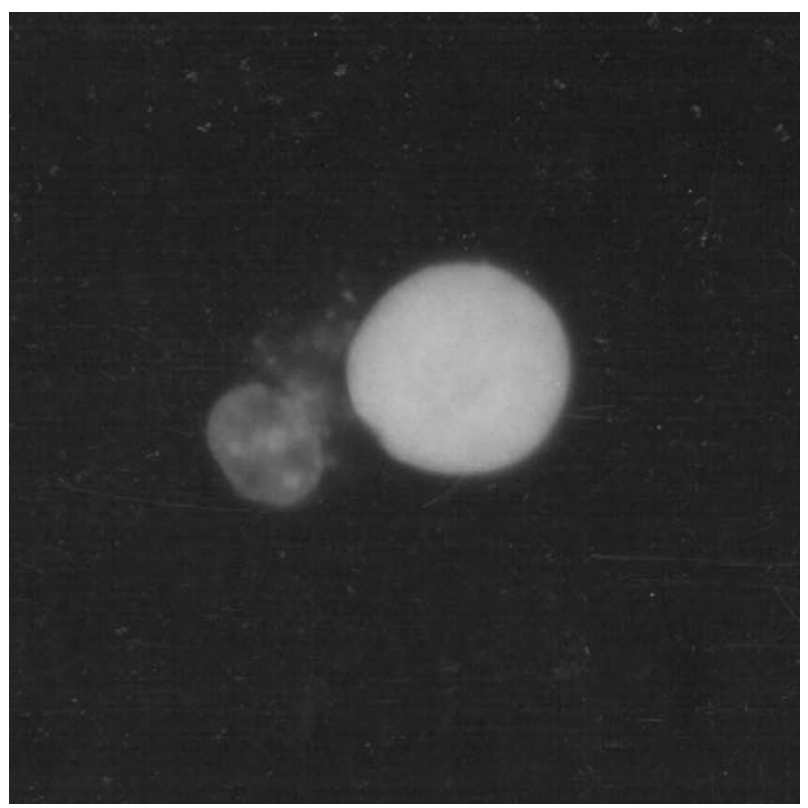

(b)

Fig. 2. T. pyriformis observed under light (a) and fluorescence (b) microscopy after $0.005 \mathrm{mg} / \mathrm{ml}$ DBSA exposure. $400 \times$ magnification.

test was performed, since no effect was observed on the cell shape or mobility.

\subsubsection{Heavy metal-treated cells}

T. pyriformis, when in contact with copper, kept their normal morphology but revealed a decrease in their mobility, which made the counting of viable/dead cells very difficult under light microscopy. Under fluorescence microscopy, while viable green cells were observed, only a few red cells were detected, even at the highest concentrations $(0.64$ and $0.69 \mathrm{mg} / \mathrm{ml})$ of copper used. Unexpectedly a new class of unstained cells was observed in all copper 
Table 2

T. pyriformis viability percentages at the highest concentration of surfactants and viability in recovered cells determined under light (LM) or fluorescence (FM) microscopy at $0.1 \mathrm{~h}, 1 \mathrm{~h}, 24 \mathrm{~h}$ and $48 \mathrm{~h}$

\begin{tabular}{|c|c|c|c|c|c|c|c|c|c|c|}
\hline & \multicolumn{8}{|c|}{ Viable cells $(\%)^{*}$} & \multicolumn{2}{|c|}{$\begin{array}{c}\text { Viable cells }(\%)^{*} \\
\text { recovered }^{\mathrm{a}}\end{array}$} \\
\hline & \multicolumn{4}{|c|}{ LM } & \multicolumn{4}{|c|}{ FM } & LM & FM \\
\hline & $0.1 \mathrm{~h}$ & $1 \mathrm{~h}$ & $24 \mathrm{~h}$ & $48 \mathrm{~h}$ & $0.1 \mathrm{~h}$ & $1 \mathrm{~h}$ & $24 \mathrm{~h}$ & $48 \mathrm{~h}$ & $24 \mathrm{~h}$ & $24 \mathrm{~h}$ \\
\hline CONTROL & $99.8 \pm 0.4$ & $99.8 \pm 0.3$ & $98.7 \pm 0.8$ & $99.4 \pm 0.5$ & $99.7 \pm 0.5$ & $99.6 \pm 0.5$ & $99.0 \pm 0.1$ & $99.4 \pm 0.5$ & - & - \\
\hline $\operatorname{SDS}(0.01 \mathrm{mg} / \mathrm{ml})$ & $85.0 \pm 3.7$ & $7.5 \pm 3.9$ & $9.5 \pm 4.1$ & $18.7 \pm 6.7$ & $92.8 \pm 5.3$ & $31.8 \pm 14.5$ & $9.8 \pm 3.9$ & $19.2 \pm 7.5$ & $99.3 \pm 0.6$ & $99.3 \pm 0.6$ \\
\hline DBSA $(0.01 \mathrm{mg} / \mathrm{ml})$ & $3.3 \pm 6.4$ & $0.3 \pm 0.8$ & $0.0 \pm 0.0$ & $0.0 \pm 0.0$ & $85.4 \pm 10.1$ & $0.5 \pm 1.2$ & $0.5 \pm 0.8$ & $0.0 \pm 0.0$ & $100.0 \pm 0.0$ & $100.0 \pm 0.0$ \\
\hline $\begin{array}{l}\text { Cetylpyridinium chloride } \\
(0.05 \mathrm{mg} / \mathrm{ml})\end{array}$ & $6.0 \pm 6.0$ & $0.0 \pm 0.0$ & $0.0 \pm 0.0$ & $0.0 \pm 0.0$ & $89.0 \pm 6.0$ & $0.0 \pm 0.0$ & $0.0 \pm 0.0$ & $0.0 \pm 0.0$ & $100.0 \pm 0.0$ & $100.0 \pm 0.0$ \\
\hline $\begin{array}{l}\text { Hexadecyltrimethylammonium } \\
\text { chloride }(0.0005 \mathrm{mg} / \mathrm{ml})\end{array}$ & $11.0 \pm 4.3$ & $0.0 \pm 0.0$ & $0.0 \pm 0.0$ & $0.0 \pm 0.0$ & $64.2 \pm 10.5$ & $0.0 \pm 0.0$ & $0.0 \pm 0.0$ & $0.0 \pm 0.0$ & $100.0 \pm 0.0$ & $100.0 \pm 0.0$ \\
\hline Triton X-100 $(0.1 \mathrm{mg} / \mathrm{ml})$ & $11.5 \pm 7.8$ & $0.0 \pm 0.0$ & $0.0 \pm 0.0$ & $0.0 \pm 0.0$ & $85.0 \pm 18.4$ & $6.0 \pm 4.7$ & $0.0 \pm 0.0$ & $0.0 \pm 0.0$ & $99.3 \pm 0.6$ & $99.3 \pm 0.6$ \\
\hline Tween-80 (100 mg/ml) & $99.7 \pm 0.8$ & $99.8 \pm 0.4$ & $99.7 \pm 0.8$ & $99.0 \pm 1.2$ & $89.2 \pm 9.1$ & $78.8 \pm 6.1$ & $83.5 \pm 7.9$ & $99.5 \pm 2.9$ & - & - \\
\hline Zwittergent-08 (20 mg/ml) & $17.0 \pm 12.9$ & $0.0 \pm 0.0$ & $0.0 \pm 0.0$ & $0.0 \pm 0.0$ & $39.4 \pm 8.0$ & $0.0 \pm 0.0$ & $0.0 \pm 0.0$ & $0.0 \pm 0.0$ & $100.0 \pm 0.0$ & $100.0 \pm 0.0$ \\
\hline Zwittergent-16 (0.2 mg/ml) & $11.6 \pm 8.0$ & $0.0 \pm 0.0$ & $0.0 \pm 0.0$ & $0.0 \pm 0.0$ & $36.4 \pm 22.6$ & $0.0 \pm 0.0$ & $0.0 \pm 0.0$ & $0.0 \pm 0.0$ & $100.0 \pm 0.0$ & $100.0 \pm 0.0$ \\
\hline
\end{tabular}

${ }^{*}$ Each value is the mean of two independent assays \pm standard deviation. $\quad{ }^{a}$ Cells removed from the highest concentration of treated culture after 1-min contact with the toxicant.

Table 3

Percentage of dead cells (D) observed under light microscopy and red cells (R) or unstained cells (U) under fluorescence microscopy at different concentrations of copper for $48 \mathrm{~h}$

\begin{tabular}{|c|c|c|c|c|c|c|c|c|c|c|c|c|c|c|c|}
\hline \multirow[b]{3}{*}{ Time (h) } & \multicolumn{15}{|c|}{ Dead cells $(\%)^{*}$} \\
\hline & \multicolumn{3}{|c|}{ Control } & \multicolumn{3}{|c|}{$0.37 \mathrm{mg} / \mathrm{ml}$} & \multicolumn{3}{|c|}{$0.55 \mathrm{mg} / \mathrm{ml}$} & \multicolumn{3}{|c|}{$0.64 \mathrm{mg} / \mathrm{ml}$} & \multicolumn{3}{|c|}{$0.69 \mathrm{mg} / \mathrm{ml}$} \\
\hline & D & $\mathrm{R}$ & $\mathrm{U}$ & D & $\mathrm{R}$ & $\mathrm{U}$ & $\mathrm{D}$ & $\mathrm{R}$ & U & $\mathrm{D}$ & R & U & D & R & $\mathrm{U}$ \\
\hline 0.1 & $0.0 \pm 0.0$ & $0.0 \pm 0.0$ & $0.0 \pm 0.0$ & $0.9 \pm 0.9$ & $0.0 \pm 0.0$ & $2.1 \pm 2.4$ & $1.2 \pm 1.4$ & $0.8 \pm 1.5$ & $21.0 \pm 12.4$ & $5.7 \pm 4.6$ & $1.6 \pm 3.2$ & $6.0 \pm 4.5$ & $9.3 \pm 3.2$ & $0.0 \pm 0.0$ & $84.2 \pm 9.8$ \\
\hline 1 & $0.2 \pm 0.2$ & $0.0 \pm 0.0$ & $0.0 \pm 0.0$ & $1.5 \pm 1.6$ & $1.2 \pm 1.0$ & $16.9 \pm 8.3$ & $4.7 \pm 3.4$ & $0.0 \pm 0.0$ & $20.0 \pm 23.0$ & $95.3 \pm 1.3$ & $0.0 \pm 0.0$ & $98.5 \pm 1.8$ & $98.9 \pm 1.4$ & $3.8 \pm 4.8$ & $92.6 \pm 4.9$ \\
\hline 24 & $0.1 \pm 0.0$ & $0.0 \pm 0.0$ & $0.0 \pm 0.0$ & $3.3 \pm 2.4$ & $18.6 \pm 7.9$ & $32.8 \pm 5.3$ & $54.9 \pm 1.3$ & $8.5 \pm 1.6$ & $54.4 \pm 9.5$ & $98.6 \pm 0.6$ & $2.8 \pm 1.9$ & $93.1 \pm 3.6$ & $99.2 \pm 1.7$ & $5.3 \pm 5.3$ & $94.7 \pm 5.3$ \\
\hline 48 & $0.2 \pm 0.1$ & $0.0 \pm 0.0$ & $0.0 \pm 0.0$ & $3.3 \pm 2.0$ & $7.6 \pm 4.5$ & $17.9 \pm 12.4$ & $44.9 \pm 6.0$ & $12.2 \pm 5.7$ & $31.1 \pm 7.2$ & $98.5 \pm 1.2$ & $3.6 \pm 2.9$ & $91.2 \pm 8.8$ & $98.4 \pm 0.4$ & $14.1 \pm 2.0$ & $85.3 \pm 1.8$ \\
\hline
\end{tabular}

* Each value is the mean of two independent assays \pm standard deviation. 
Table 4

Comparison of viable cell percentages among control, copper, and after copper exposure in the recovery assay, determined under light (LM) or fluorescence (FM) microscopy

\begin{tabular}{|c|c|c|c|c|c|c|}
\hline \multirow[b]{3}{*}{ Time (h) } & \multicolumn{6}{|c|}{ Viable cells $(\%)^{*}$} \\
\hline & \multicolumn{2}{|c|}{ Control } & \multicolumn{2}{|c|}{$0.69 \mathrm{mg} / \mathrm{ml}$} & \multicolumn{2}{|c|}{ Recovered $^{\mathrm{a}}$} \\
\hline & LM & FM & LM & FM & LM & FM \\
\hline 24 & $100 \pm 0.0$ & $100 \pm 0.0$ & $1.6 \pm 0.8$ & $0.0 \pm 0.0$ & $1.7 \pm 2.4$ & $3.8 \pm 2.8$ \\
\hline 48 & $100 \pm 0.0$ & $100 \pm 0.0$ & $0.0 \pm 0.0$ & $0.0 \pm 0.0$ & $0.5 \pm 0.7$ & $0.2 \pm 0.5$ \\
\hline
\end{tabular}

* Each value is the mean of two independent assays \pm standard deviation. a Cells removed from the highest concentration treated culture after 1-min contact with the metal.

concentrations, but not in the control. Table 3 shows the percentage of dead cells obtained by the two different methods, distinguishing the red and unstained classes in the fluorescent observations. For concentrations to 0.37 and $0.55 \mathrm{mg} / \mathrm{ml}$ of the metal, with few exceptions, the percentage of unstained cells was higher than dead cells. For the two highest concentrations studied, the percentage of unstained cells was closest to that of dead cells, especially with increasing time of incubation. Assuming that both red and unstained cells observed under fluorescence microscopy corresponded to dead cells observed under light microscopy, even at lower concentrations of metal and less time of incubation, higher percentages were obtained. Furthermore, in order to confirm that unstained cells were correctly counted as dead cells, a recovery assay was performed. Table 4 shows comparable percentages of viable cells obtained by light and fluorescence microscopy. It is clearly demonstrated that unstained cells were cells condemned to die, since no growth was observed in the recovery assay, even though a low percentage $(<2 \%)$ of viable cells were found at time $0.1 \mathrm{~h}$. Taking into account this result, unstained cells should be added to red cells as nonviable.

Zinc affected T. pyriformis morphology and mobility in a dose-dependent mode. Cells with increased cell volume, irregular shapes and a very large vacuole at the posterior end were founded in the cultures treated with the highest concentration $(0.25 \mathrm{mg} / \mathrm{ml})$ of zinc after $1 \mathrm{~h}$ of exposure (Fig. 3a). The loss of mobility by those cells once again made it very difficult to count live/dead protozoa. Using the fluorescent method, the large and irregular shaped cells showed an outsized unstained vacuole (Fig. 3b) and very bright green fluorescent vacuoles. The nucleus did not stain red, so they should be included on the green (live) count at earlier times of exposure.

Some recovery assays were performed to ensure that cells could recovery their normal shape (Fig. 4). Recovery performed following the one-minute procedure clearly showed that $T$. pyriformis was able to recover the normal shape and its capacity to divide. As cells were morphologically normal after one minute of zinc contact, two other recovery assays were made at $0.1 \mathrm{~h}$ and $1 \mathrm{~h}$. After one hour of exposure, cells were not able to recover and showed the same growth pattern as exposure at $0.25 \mathrm{mg} / \mathrm{ml}$. For $0.1 \mathrm{~h}$ the growth recovery pattern was similar to that for 1-min recovery.

\subsection{Fluorescence-based and direct-count cytotoxicity assays}

T. pyriformis exhibited a dose-dependent response to all the toxic compounds used, i.e. increasing toxicant concentrations caused decreasing viability values. Light and fluorescence microscopy counting were used as comparative methods to determine cell viability at different concentrations and time exposures to the surfactants and to the heavy metals studied.

\subsubsection{Surfactant-treated cells}

The $\mathrm{LC}_{50}$ values obtained from the triplicate experiments for all the surfactants (except for Tween-80) were calculated and shown in Table 5. After $1 \mathrm{~h}$ of exposure, cytotoxicity measured by light microscopy counting had a similar rank order as cytotoxicity measured by the calcein AM/EthD-1 assay $\left(r^{2}=0.999\right)$. Therefore a very high correlation $\left(r^{2}=\right.$ 0.999 ) between the two methods was also observed for 24 $\mathrm{h}$ of exposure. Highly correlated values $\left(r^{2}=0.971\right)$ were obtained in $\mathrm{LC}_{50}-0.1 \mathrm{~h}$ versus $\mathrm{LC}_{50}-24 \mathrm{~h}$ by the two methods, despite a 10-fold rank order difference of SDS, DBSA, cetylpyridinium chloride, hexadecyltrimethylammonium chloride and Triton X-100.

\subsubsection{Heavy metal-treated cells}

In copper-treated cells the fluorescent method appeared to be more sensitive in the detection of damaged cells even at a short exposure time of $0.1 \mathrm{~h}$ (Fig. 5). This could be a reason for the disparity of viability values between the two methods. Furthermore, at $0.1 \mathrm{~h}$, viability was not affected by any concentration of copper tested under light microscopy, but under fluorescence, a dose dependent response was observed immediately after the metal addition. Accordingly, increasing copper concentrations caused decreasing viability values. Above $1 \mathrm{~h}$ and high concentrations of metal (0.64$0.69 \mathrm{mg} / \mathrm{ml}$ ) similar low viability values were found in both methods. At the intermediate concentration of copper $(0.55 \mathrm{mg} / \mathrm{ml})$, discrepancies in the results were obtained between the two methods at short exposure times $(0.1$ and $1 \mathrm{~h}$ ). While light microscopy counting suggested that copper 


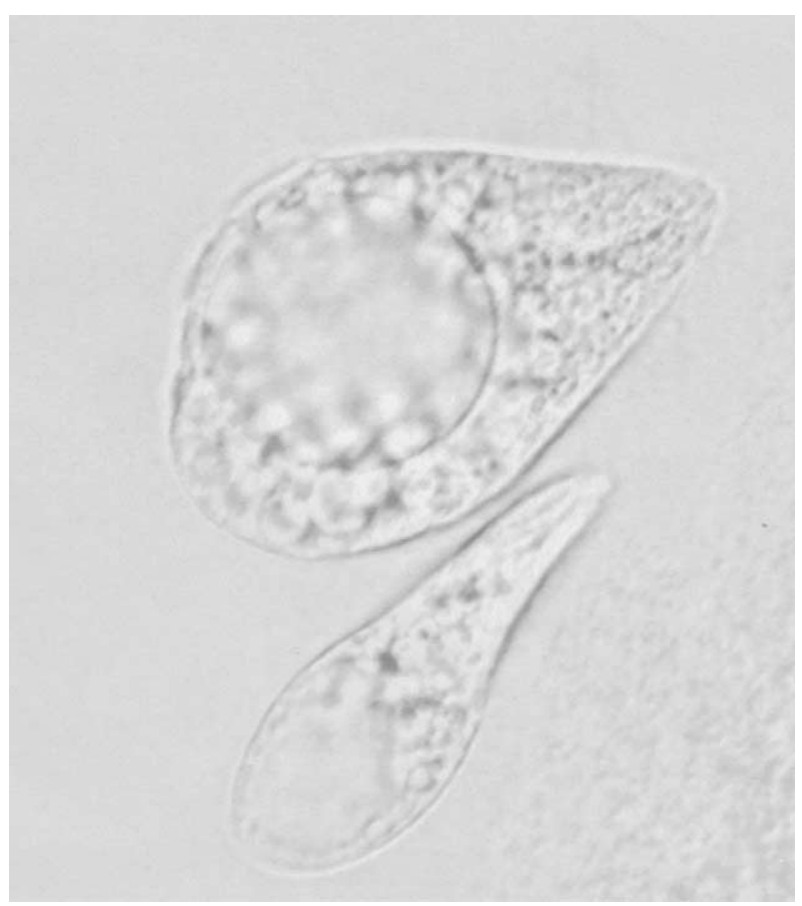

(a)

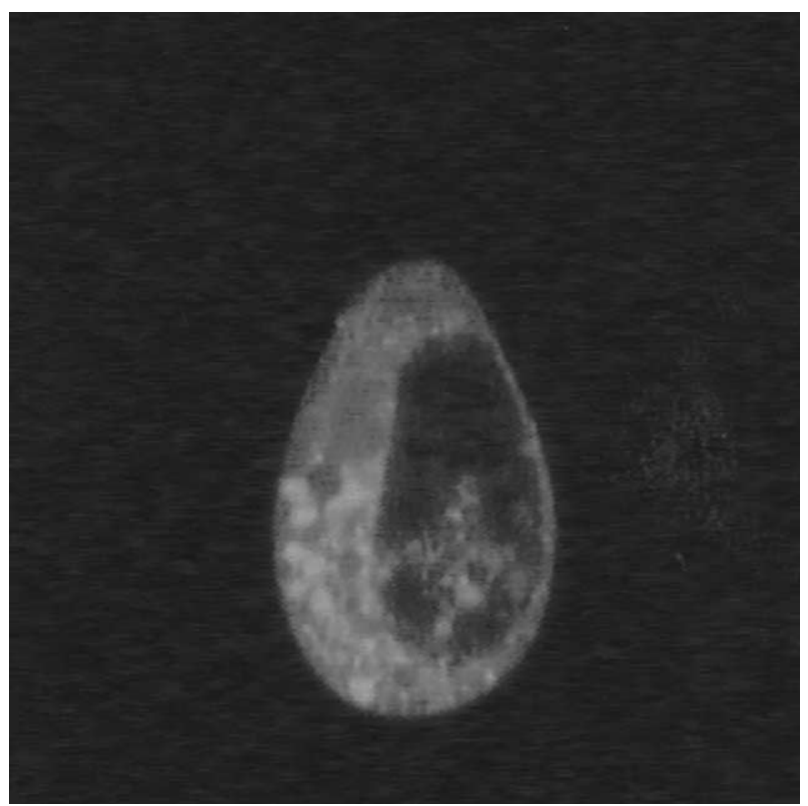

(b)

Fig. 3. T. pyriformis observed under light (a) and fluorescence (b) microscopy after $0.25 \mathrm{mg} / \mathrm{ml}$ zinc exposure. $400 \times$ magnification.

did not affect cells at the two first times of the experiment, fluorescence observation indicated that at least $20 \%$ of cells were already dead. After $24 \mathrm{~h}$ of treatment, viability values were analogous for both methods. Higher sensitivity of the fluorescent method was supported by data obtained at lower concentrations of copper treatment. Moreover, in all experiments, the time-dependent response of treated cells was verified by fluorescence microscopy, while under light microscopy, cells seemed not to be affected.

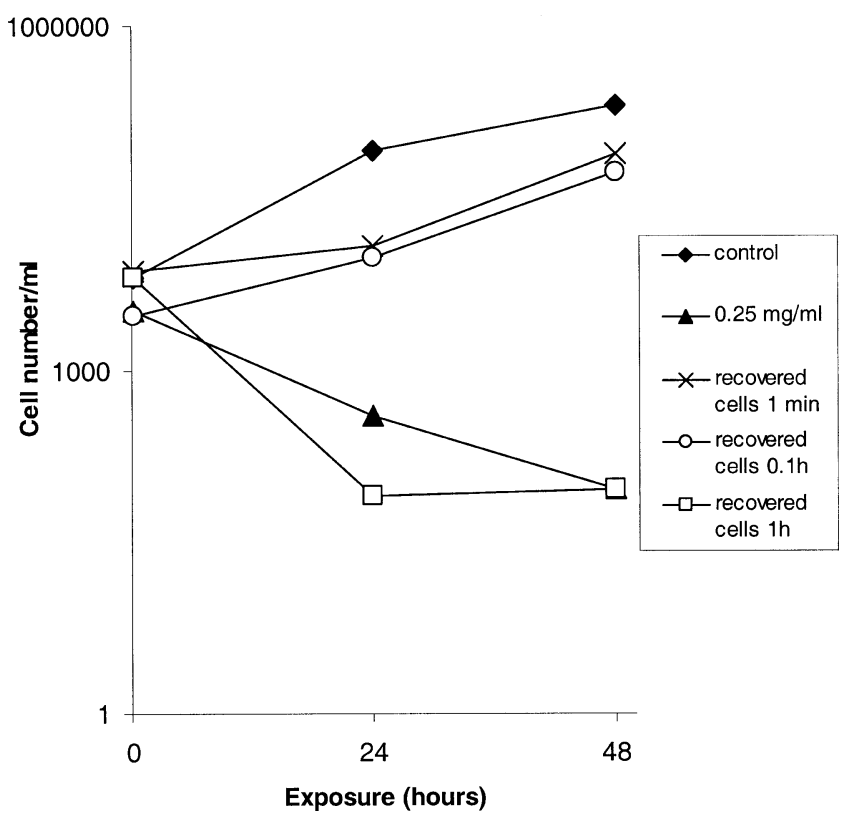

Fig. 4. Effect in T. pyriformis population growth on control, $0.25 \mathrm{mg} / \mathrm{ml}$ treated cells and recovered cells after $1 \mathrm{~min}, 0.1 \mathrm{~h}$ and $1 \mathrm{~h}$ contact of $0.25 \mathrm{mg} / \mathrm{ml}$ zinc exposure. Data are means of two independent assays.

At short exposure times $(0.1$ and $1 \mathrm{~h})$ to zinc, in contrast to copper, light microscopy was revealed to be a more sensitive method than fluorescence, although, after $24 \mathrm{~h}$ of exposure, similar viability values were found for the two methods (Fig. 6). Unlike copper effects, zinc effects were detected by light microscopy counting after a brief exposure $(0.1 \mathrm{~h})$, and a dose-dependent response was observed. At that time no dose response was observed by fluorescence counting in any heavy metal concentrations. Even so, zinc exhibited a time-dependent response at long-term exposure (after $24 \mathrm{~h}$ ) for both methods.

\section{Discussion}

The purpose of this work was to apply a procedure commonly used in animal cells in order to determine viability in protozoa. To achieve this aim the 48-h assay was used to assess acute toxicity on the ciliate T. pyriformis. The live/dead viability/cytotoxicity assay should allow simple, quantitative and reproducible measurements of viability when used with advanced techniques of quantification and data analysis, such as flow cytometry, fluorometry [6] and image analysis [14].

Recently Larsen and collaborators [7] proposed an international Pilot Ring test in order to standardize a growth inhibition test protocol with $T$. pyriformis. They concluded that the Tetrahymena test is recommended for ecotoxicological screening purposes, being an ecologically relevant supplement to aquatic toxicity testing. Population growth impairment is the most sensitive and often-used sublethal toxic endpoint [21] and reveals predominantly higher sen- 
Table 5

Comparative $\mathrm{LC}_{50}$ values $(*)$ of seven surfactants at $0.1 \mathrm{~h}, 1 \mathrm{~h}$ and $24 \mathrm{~h}$ determined by light microscopy (LM) and by fluorescence microscopy (FM)

\begin{tabular}{|c|c|c|c|c|c|c|}
\hline \multirow[t]{2}{*}{ Surfactants } & \multicolumn{3}{|c|}{ LM } & \multicolumn{3}{|c|}{ FM } \\
\hline & $0.1 \mathrm{~h}$ & $1 \mathrm{~h}$ & $24 \mathrm{~h}$ & $0.1 \mathrm{~h}$ & $1 \mathrm{~h}$ & $24 \mathrm{~h}$ \\
\hline SDS & 0.036 & 0.005 & 0.004 & 0.078 & 0.007 & 0.004 \\
\hline DBSA & 0.007 & 0.004 & 0.004 & 0.037 & 0.004 & 0.004 \\
\hline Cetylpyridinium chloride & 0.003 & 0.002 & 0.003 & 0.025 & 0.003 & 0.003 \\
\hline Hexadecyltrimethylammonium chloride & 0.0003 & 0.0002 & 0.0002 & 0.001 & 0.0003 & 0.0002 \\
\hline Triton $\mathrm{X}-100$ & 0.067 & 0.054 & 0.045 & 0.36 & 0.067 & 0.048 \\
\hline Zwittergent-08 & 14.83 & 11.94 & 12.29 & 24.59 & 14.94 & 12.82 \\
\hline Zwittergent-16 & 0.14 & 0.08 & 0.08 & 0.20 & 0.11 & 0.10 \\
\hline
\end{tabular}

(*) Each value was obtained by linear regression of the mean count of dead cells.

sitivities than tests reflecting viability, respiration or the chemosensory responses [22]. Moreover, growth/mortality bioassay using microscopic observation of the morphological changes, at low magnification, is a simple and reproducible technique that does not require technical expertise or operational expenses [15]. Nevertheless, some limitations were detected in this study that make it unsuitable for several toxicants. In particular, recognizing dead cells was sometimes ambiguous, since non-motile cells as well as cells with altered shape were counted as dead cells. However, we found that the observations made under light microscopy, $0.1 \mathrm{~h}$ of exposure to the highest concentration of surfactants, except for Tween-80, underestimated viability. In fact, several abnormally appearing cells were not dead, and even recovered their normal shape immediately after toxicant removal and started to grow in the recovery assay. All surfactants tested in this work had reversible effects at the highest concentration, if after one minute of contact, treated cells were diluted to lower detergent concentrations. Agents such as ethidium bromide [12] and dimethyl sulfoxide [16] were reported to alter the morphology of Tetrahymena sp. but have reversible effects and cells were able to grow after toxicant removal.

The live/dead assay was found to be a very sensitive method for toxicants that damaged the cell membrane, given that all green cells were established as viable cells even with an altered shape. Tween- 80 seemed to be an exception since no morphological or swimming pattern alterations were detected under light microscopy at any time of the experiment at any concentration used. Nevertheless a strong decrease in fluorescence intensity at the highest Tween-80 concentration could indicate cellular toxicity, which only was detected by the calcein AM/EthD-1 method. This confirms the higher sensitivity of fluorescence over former light microscopy counting for surfactants.

A very high correlation $\left(r^{2}=0.999\right)$ was obtained with $\mathrm{LC}_{50}$ above $24 \mathrm{~h}$ of toxicant exposure in both methods. Despite the 10 -fold rank order difference $\mathrm{LC}_{50}$ calculation after a brief $(0.1 \mathrm{~h})$ and at a 24-h exposure, a good correlation $\left(r^{2}=0.971\right)$ was obtained between the two methods. This suggested that viability could be assessed by the two
(A)

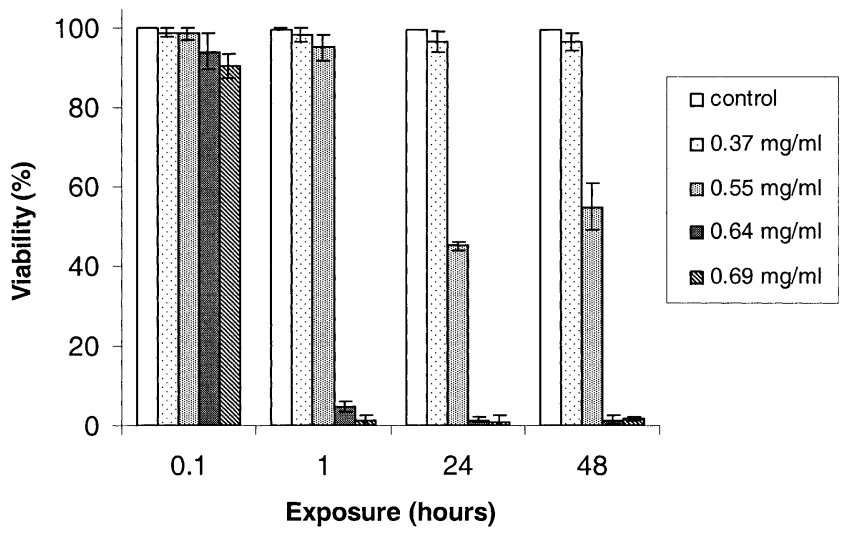

(B)

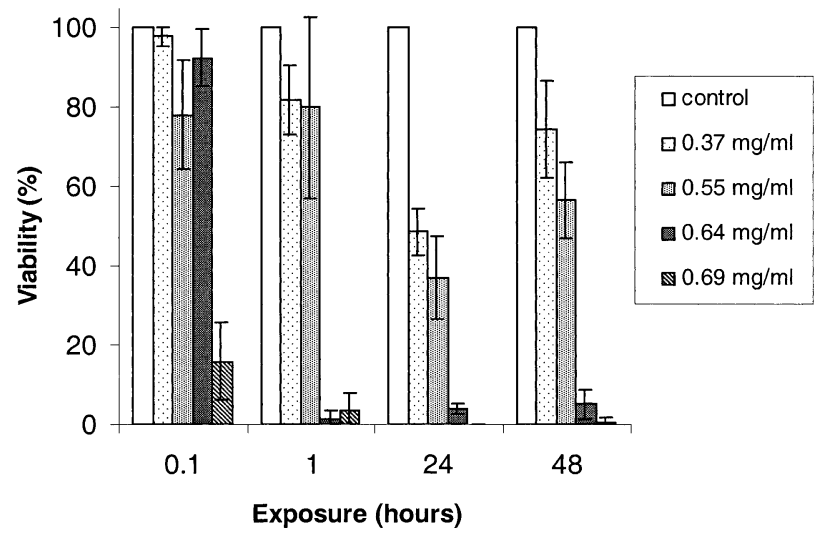

Fig. 5. Viability of T. pyriformis exposed to different concentrations of copper for $48 \mathrm{~h}$ using light (A) and fluorescence (B) microscopy counting. Values presented are the averages of three independent assays. Bars represent standard deviations.

methods even at early stages, so the information could be obtained within one hour. Nevertheless short-time exposures may indicate a transition cellular state that could lead to inaccurate results if care is not taken to perform a previous study before using more advanced techniques such as flow cytometry. 
(A)

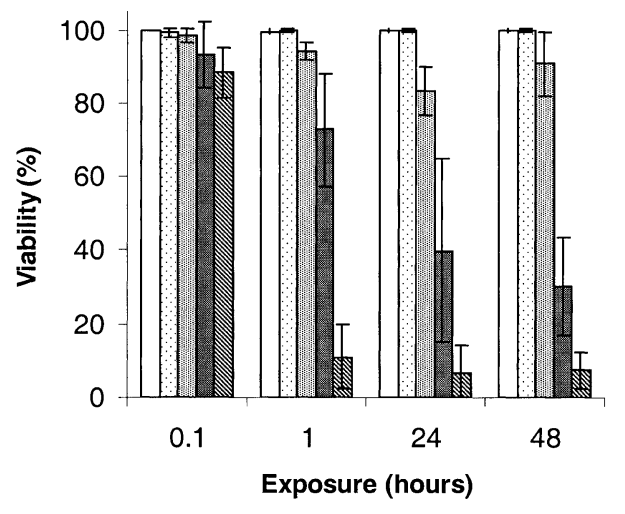

(B)

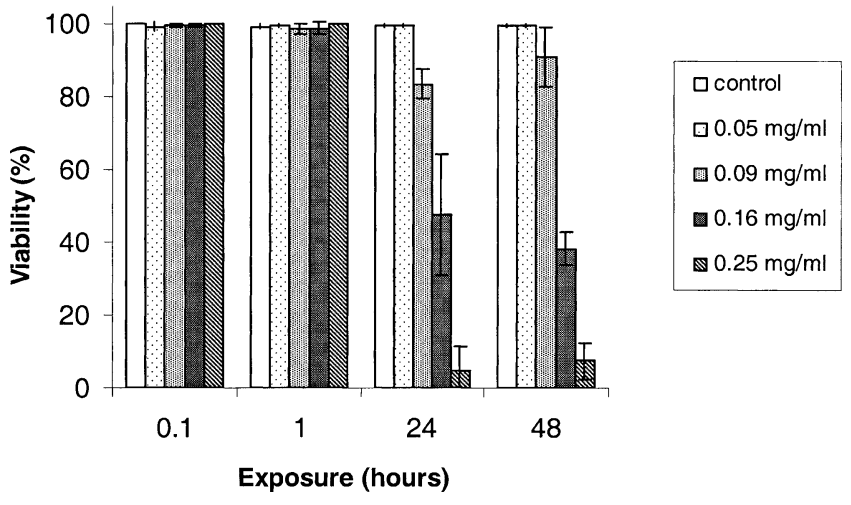

Fig. 6. Viability of T. pyriformis exposed to different concentrations of zinc for $48 \mathrm{~h}$ using light (A) and fluorescence (B) microscopy counting. Values presented are the averages of three independent assays. Bars represent standard deviations.

T. pyriformis has been used extensively in studies on effects of heavy metals. Although the mechanisms by which heavy metals affect the microorganisms is not clear, authors have described copper as an essential metal that accumulated in the mitochondria [29] with its distribution observable as small electron-dense dots $[17,18]$. Alteration on Tetrahymena morphology after aluminium exposure was reported by Sauvant and collaborators [26] who observed the presence of large and irregular-shaped monster cells in treated cultures. These morphological abnormalities were detected in zinc-treated cells but not in copper cultures.

In this study the cellular membrane of $T$. pyriformis seemed not to be affected by the concentrations of copper used, since cells did not incorporate EthD-1 dye at an early exposure time. Although the organisms decreased swimming velocity, becoming almost immobile. In coppertreated cultures light microscopy observations provided an overestimate of viability when compared to the fluorescent microscopy results, at $0.1 \mathrm{~h}$, for the highest concentration of copper $(0.69 \mathrm{mg} / \mathrm{ml})$. Indeed, when transferred to dilute medium treated cells did not grow in the recovery assays, showing they were condemned to die.

The reduced ability of cells to take up and hydrolyze calcein AM and retain the hydrolyzed form has been proposed as a measure of cellular toxicity [10] irrespective of how xenobiotics may cause the decrease in fluorescence intensity [1]. This could explain the strong decrease in fluorescence intensity despite different mechanisms of toxicant action. Since no unstained cells were found in the control, it is possible that the copper presence could directly or indirectly inhibit enzyme activities. Consequently, this could lead to inhibition of the access of calcein AM to the cell and/or the action of esterases in the conversion to fluorescent calcein. Unstained cells were difficult to observe under fluorescence microscopy and their presence had to be confirmed by light microscopy. Unlike the case after copper exposure, no unstained cells were observed after zinc exposure; instead bright green cells with an altered shape were detected in the Tetrahymena population. Acetoxymethyl (AM) esters have been widely used as intracellular ion indicators since some metals can interfere with the fluorescence intensity of calcein by forming calcein/metal ion complexes. Moreover, the fluorescence of calcein is strongly quenched by several metals ions such $\mathrm{Co}^{2+}, \mathrm{Ni}^{2+}, \mathrm{Cu}^{+}, \mathrm{Cu}^{2+}$ and $\mathrm{Tb}^{3+}$ at physiological pH [6]. In contrast, since calcein binds $\mathrm{Zn}^{2+}, \mathrm{Ca}^{2+}$, $\mathrm{Mg}^{2+}$ and other metals leading to metal ion complex [6], this polyanionic fluorescein derivative has been used as a fluorescent indicator for zinc concentration [13]. It is safe to assume that if fluorescence is enhanced by the increasing zinc concentration, then a measure of the metal concentration can be calculated. For the reasons stated above, which might explain the unstained cells (for copper) and the increase of fluorescence (for zinc), it should be considered that calcein may not be a good viability marker in the presence of metals, though it worked well with membrane-active chemical agents.

DNA specific stains such as Hoechst 33342 or DAPI (4',6-diamidino-2-phenylindole) could, in principle, be used to detect all cells, viable or non-viable, possibly clarifying non-staining of cells, for which no experimental explanation has yet been found. DAPI has been used in the quantification of protozoa in infiltration systems [27]. Propidium iodide (PI), another acid nucleic binding dye was used to assess cell viability from bivalves [2] and microalgae [4] exposed to heavy metals.

\section{Conclusions}

Direct counting under light microscopy provided erroneous estimates of viability when the counting was done less than $1 \mathrm{~h}$ after toxicant exposure. The fluorescent method utilized in this study appears to offer several advantages over the traditional method, in surfactants. It gives a more accurate and sensitive estimate of viability based on earlier detection of damaged cells. However, due to the dif- 
ferent mechanism of toxicity of each chemical agent, if we intend to assess viability by the calcein AM/EthD1 assay, we should take into account recovery studies in order to standardize the assay for each experimental situation.

\section{Acknowledgements}

The authors acknowledge the financial support provided by the Instituto de Biotecnologia e Química Fina (IBQF). Nicolina Dias was supported by grant PRAXIS $\mathrm{XXI} / \mathrm{BD} / 20328 / 99$.

\section{References}

[1] P. Bogaerts, J. Bohatier, F. Bonnemoy, Use of the ciliated protozoan Tetrahymena pyriformis for the assessment of toxicity and quantitative structure-activity relationships of xenobiotics: comparison with the microtox test, Ecotoxicol. Environ. Saf. 49 (2001) 293-301.

[2] P. Brousseau, J. Pellerin, Y. Morin, D. Cyr, B. Blakley, H. Boermans, M. Fournier, Flow cytometry as a tool to monitor the disturbance of phagocytosis in the clam Mya arenaria hemocytes following in vitro exposure to heavy metals, Toxicol. 142 (2000) 145-156.

[3] C.J. Cao, R.J. Mioduszewski, D.E. Menking, J.J. Valdes, V.I. Cortes, M.E. Eldefrawi, A.T. Eldefrawi, Validation of the cytosensor for in vitro cytotoxicity studies, Toxicol. in vitro 11 (1997) 285-293.

[4] D. Franqueira, M. Orosa, E. Torres, C. Herrero, A. Cid, Potential use of flow cytometry in toxicity studies with microalgae, Sci. Total Environ. 247 (2000) 119-126.

[5] R. Gatti, S. Belleti, G. Orlandini, O. Bussolati, V. Dall'Asta, G.C. Gazzola, Comparison of annexin V and calcein-AM as early vital markers of apoptosis in adherent cells by confocal laser microscopy, J. Histochem. Cytochem. 46 (1998) 895-900.

[6] R.P. Haugland (Ed.), Handbook of Fluorescent Probes and Research Chemicals, Molecular Probes, Leiden, 1996, pp. 366-376.

[7] J. Larsen, T.W. Schultz, L. Rasmussen, R. Hooftman, W. Pauli, Progress in an ecotoxicological standard protocol with protozoa: results from a pilot ring test with Tetrahymena pyriformis, Chemosphere 35 (1997) 1023-1041.

[8] R. Lichtenfels, W.E. Biddison, H. Schulz, A.B. Vogt, R. Martin, CARE-LASS (calcein-release-assay), an improved fluorescence-based test system to measure cytotoxic T lymphocyte activity, J. Immunol. Methods 172 (1994) 227-239.

[9] G. Liminga, P. Nygren, S. Dhar, K. Nilsson, R. Larsson, Cytotoxic effect of calcein acetoxymethyl ester on human tumor cell lines: drug delivery by intracellular trapping, Anticancer Drugs 6 (1995) 578-585.

[10] I.C. MacCourbey, P.L. Moore, R.P. Haugland, Quantitative fluorescence measurement of cell viability (cytotoxicity) with a multi-well plate scanner, J. Cell Biol. 111 (1990) 303.

[11] P. Madoni, D. Davoli, G. Gorbi, Acute toxicity of lead, chromium and other heavy metals to ciliates from activated sludge plants, Bull. Environ. Contam. Toxicol. 53 (1994) 420-425.
[12] R.R. Meyer, C.R. Boyd, D.C. Rein, S.J. Keller, Effect of ethidium bromide on growth and morphology of Tetrahymena pyriformis, Exp. Cell Res. 70 (1971) 233-237.

[13] M. Morters, H.J. Bart, Fluorescence-indicated mass transfer in reactive extraction, Chem. Eng. Technol. 23 (2000) 353-359.

[14] A. Nicolau, N. Dias, M. Mota, N. Lima, Trends in the use of protozoa in the assessment of wastewater treatment, Res. Microbiol. 152 (2001) $621-630$

[15] A. Nicolau, M. Mota, N. Lima, Physiological responses of Tetrahymena pyriformis to copper, zinc, cyclohexymide and Triton X-100, FEMS Microbiol. Ecol. 30 (1999) 209-216.

[16] J.R. Nilsson, Effects of DMSO on vacuoles formation, contractile vacuole function, and nuclear division in Tetrahymena pyriformis GL, J. Cell Sci. 16 (1974) 39-47.

[17] J.R. Nilsson, Effects of copper on phagocytosis in Tetrahymena, Protoplasma 109 (1981) 359-370.

[18] J.R. Nilsson, Tetrahymena in cytotoxicology: with special reference to effects of heavy metals and selected drugs, Eur. J. Protistol. 25 (1989) $2-25$.

[19] H.B. Oral, A.J.T. George, D.O. Haskard, A sensitive fluorometric assay for determining hydrogen peroxide-mediated sublethal and lethal endothelial cell injury, Endothelium 6 (1998) 143-151.

[20] N.G. Papadopoulos, G.V.Z. Dedoussis, G. Spanakos, A.D. Gritzapis, C.N. Baxevanis, M. Papamichail, An improved fluorescence assay for the determination of lymphocyte-mediated cytotoxicity using flow cytometry, J. Immunol. Methods 177 (1994) 101-111.

[21] W. Pauli, S. Berger, L. Jaskulka, S. Schmitz, A case for the inclusion of a protozoan test in aquatic toxicity assessment using Tetrahymena, Sci. Total Environ. Supplem. (1993) 779-786.

[22] W. Pauli, S. Berger, Toxicological comparisons of Tetrahymena species, end points and growth media: supplementary investigations to the pilot ring test, Chemosphere 35 (1997) 1043-1052.

[23] E. Piccinni, P. Irato, O. Coppelotti, L. Guidolin, Biochemical and ultrastructural data on Tetrahymena pyriformis treated with copper and cadmium, J. Cell Sci. 88 (1987) 283-293.

[24] M.M. Roden, K.H. Lee, M.C. Panelli, F.M. Marincola, A novel cytolysis assay using fluorescent scanning technology, J. Immunol. Methods 226 (1999) 29-41.

[25] M.P. Sauvant, D. Pepin, E. Piccini, Tetrahymena pyriformis: a tool for toxicological studies. A review, Chemosphere 38 (1999) 1631-1669.

[26] M.P. Sauvant, D. Pepin, J. Bohatier, C.A. Groliere, Effects of chelators on the acute toxicity and bioavailability of aluminium to Tetrahymena pyriformis, Aquat. Toxicol. 47 (2000) 259-275.

[27] T.K. Stevik, J.F. Hanssen, P.D. Jenssen, A comparison between DAPI direct count (DDC) and most probable number (MPN) to quantify protozoa in infiltration systems, J. Microbiol. Methods 33 (1998) 1321.

[28] L. Twagilimana, J. Bohatier, C.A. Groliere, F. Bonnemoy, D. Sargos, A new low-cost microbiotest with the protozoan Spirotomum teres: culture conditions and assessment of sensitivity of the ciliate to 14 pure chemicals, Ecotoxicol. Environ. Saf. 41 (1998) 231-244.

[29] T. Wakatsuki, Y. Tasaki, H. Imahara, Respiratory inhibition by copper in Tetrahymena pyriformis GL, J. Ferment. Technol. 64 (1986) 119127.

[30] X.M. Wang, P.I. Terasaki, G.W. Rankin Jr., D. Chi, H.P. Zhong, S. Hardy, A new microcellular cytotoxicity test based on calcein AM release, Hum. Immunol. 37 (1993) 264-270. 